\title{
CORRIGENDUM
}

\section{Organ-specific features of natural killer cells}

Fu-Dong Shi, Hans-Gustaf Ljunggren, Antonio La Cava and Luc Van Kaer

Nature Reviews Immunology 11, 658-671 (2011)

In the original version of this article, in the section under the subheading "CNS-specific NK cells in disease" on page 668, the humanized antibody daclizumab was incorrectly described as being specific for the IL-2 receptor $\beta$-chain (CD122).

The corrected sentence now reads: "These findings might be relevant to the mode of action of daclizumab, a humanized antibody specific for the IL-2 receptor $\alpha$-chain (CD25)”. The authors apologize for this error. 